\title{
Supply chain control: Trade-offs and system requirements
}

\author{
N P Leach, C Makatsoris, H D Richards.
}

Human Systems Management. Amsterdam: 1997. Vol. 16, Iss. 3; pg. 159, 11 pgs

\begin{abstract}
A paper describes the underlying forces which drive change in manufacturing enterprises and supply chains. It sets out the complexities in modern capitalism and global economics and illustrates the trade-offs that can be made. IT systems which are required to assist improvements to both customer service and enterprise manufacturing performance are explained, alluding to the special case for the semiconductor industry. Arguments are presented showing how the new tools being developed with the ESPRIT project 20544, X-CITTIC, will satisfy the control needs for a virtual enterprise. This paper describes the underlying forces which drive change in manufacturing enterprises and supply chains. It sets out the complexities in modem capitalism and global economics and illustrates the trade-offs that can be made. IT systems which are required to assist improvements to both customer service and enterprise manufacturing performance are explained alluding to the special case for the semiconductor industry. Finally it shows how the new tools being developed with the ESPRIT project 20544, XCITTIC, will satisfy the control needs for a virtual enterprise.
\end{abstract}

Keywords: Supply chain, virtual enterprise, planning, control

\section{Introduction}

There is no economic order. Global interactive, trans-national industries we have today introduce more asymmetry between industrial nations. Time, money and uncertainties pervade all of economic life and industrial trade. Local national political intervention, or non-intervention by government, often using out-of-date economic theory, may change local competitive pressures, affecting Small and Medium Size Enterprises (SMEs) in the main who operate in more local economies putting them at a disadvantage or encouraging their entrepreneurism. On the other hand multinational companies are able to cope more with pressure disadvantage by balancing the way they do business through manipulation of money.

However, the development of communications technologies, cheaper transport availability, the technology for transporting perishable goods, allows opportunities for all industrial enterprises, large or small, in the global market place. The open market of the European Union and the GATT agreements signed in 1994 by more than 100 industrial nations has also alleviated some of the problems resulting from trade restrictions. These opportunities may be improved by a better understanding of crucial factors such as time, money and uncertainty and how to deal effectively with them. 
The work of Alfred Chandler [1] showed through historical records for the top 200 companies in the USA, UK and Germany, that in the period 1870 to 1970 , costs continued to fall as production increased. These enterprises invested in volume production, in marketing, in distribution and purchasing, and they recruited managers who could operate the business effectively. Their operational costs were lower than their competitors and they worked to keep them that way. Since 1970 Japan and the tiger economies of the Pacific Rim nations have made their economic presence felt, not just by introducing new manufacturing methods, but by recognising the importance of the workforce commitment in quality and production improvements. Additionally Japan in particular recognised the importance of establishing cooperative relationships with suppliers to ensure quality. Quality improvement became a new driving force through the 80's and transformed the service to the customer in terms of quality of product but at the same time with no detriment to price offered.

As an illustration, the production of new silicon chips, a new pharmaceutical drug, a new prepared food, a software tool, requires considerable $R \& D$ and engineering investment but is recouped by comparatively cheap production the cost of which falls with volume. However, the customer benefits again as variety and quasi-customised products can be offered at little extra cost. So, consumer demand is stimulated further.

The rigorous competition leads some business men in western nations to complain about unfair competition and the need for level playing fields. But the playing fields will always be uneven in the world arena, giving both advantages and disadvantages to the industrial competing players. There are no universal rules or fair play, only some regulatory ones, such as GATT.

Repositioning for the hard and unremitting competition for the future is critical for every enterprise. Any waste has to be cast off:

- organisations have to be set up for greater effectiveness,

- less constrained internal bureaucracies,

- human relationships improved to hone an efficient and continuously improving unit,

- education and training to provide the necessary skills,

- concentration on core enterprise competence,

- acquire customer lock-ins by needed and intime new product designs,

- $\quad$ strengthen relationships with suppliers of materials and services to offset delivery risk,

- invest at the right time to secure growth, sustained market position and new market penetrations.

- Consumer and customer power has to be properly recognised in that poor performance is magnified such that it is hard to regain confidence. 
- Expectations now and for the future for customers and enterprise owners or shareholders must be satisfied.

These demanding features and the perspective of current and future economic climate has caused many enterprises to be in upheaval, seeking ways and means by which they may change for the better and be prepared and equipped to gain competitive edge. Foremost in their thinking has been to change business processes to allow better organisations which are flexible and in tune with the new enterprise vision and its goals. Control of manufacturing and the supply chain is part of this visionary change. Management in its entirety needs to ensure productive flow satisfying customer expectations, long term enterprise viability and satisfaction of its owners and shareholders. This paper deals with some these aspects in supply chain control, the trade-offs which have to be considered, and system requirements which will assist the establishment of new enterprise goals through better means of planning and control of logistic resources to the benefit of customers and enterprise.

\section{Industrial change and challenges}

As we have seen there are many challenges facing industry. They are different dependent upon size, type of business, markets, and their experience and plans for use of IT, but all must meet the challenge. There is no immunity.

A key challenge for supply chain management is to balance customers needs with the cost of inventory. Inventory must be optimised for both customer service and enterprise economics, not only for the end customer but also at the intermediate ones in the supply chain to attain a fair but balanced distribution of inventory cost between customers and suppliers as well as its overall minimisation. The approach must not be obscured and should ensure that the supply chain is assessed as a whole. Seeing the large picture is of paramount importance. Any system has to be capable of responding to its inherent dynamics and static rules and policies have little validity here. Success may be measured by how well it responds to input in an efficient, co-ordinated and co-operative manner to provide an output which is consistent, coherent and effective in maximising returns to the enterprise.

Such customer needs are:

- A fast interactive exchange to agree an order deivery date-time.

- A short duration time from order placement to receipt of order on the site required.

- A guaranteed reliability of receiving the whole order to the agreed promise.

- The product(s) to have the right price and quality.

- And specifically for intermediate customers in the supply chain, the confidence to reduce front-end buffer stocks which ensure non-stop manufacturing. 
An enterprise also has to take account of other outside influences. Examples of these are the parent company management board and managing director, stock market valuation and shareholder aspirations. In some complex organisations the parent company does not always have in mind the best long-term interests for a particular enterprise. This may now be partly reflected by the way the stock markets are turning away from earnings per share, EPS, as a way of measuring company performance (this measure is too easily manipulated) to one which reflects cash generation over a long term, that is, a cash-based measurement based on cash flow return on investment. The challenge for the enterprise is to have internal measures which strongly relate to this measure of performance which the workforce understands and can continuously target to make improvements. But there has been little attempt yet to harmonise financial measures with operations and customer support measures. Further improvements to competitive edge through supply chain management will drive this harmonisation.

Door-to-door service is also a challenge for it probably involves, in modern manufacturing companies, an outsourced transport service provider, so that the final stage of delivery performance is governed by their performance. Intermediate deliveries through the supply chain are also very relevant too in distributed manufacturing networks, and for material supply in controlling the logistic flow. Most freight, currently $70 \%$, within the European market is by road transport. The European Union has plans to greatly extend the current road networks and to implement pricing policies to encourage other forms of transport, when possible, so as to lessen road congestion. Even so, road transport in the year 2000 is expected to be double the figure measured in 1975 . When road transport currently accounts for $80 \%$ of carbon dioxide emissions other factors too have to be taken into account. Nevertheless, it is expected through new technology for transport positioning and route navigation aids that transportation will be more easily monitored and will enable in the future even closer control of the supply flow.

The shrinking of organisations and pulling back to core competencies inevitably leads to utilising further outsourced services. These are now used for most enterprise functions from design to manufacturing. They are used not without extra cost because effort is required to monitor quality and supply. Good relationships are required to ensure good co-operation, but at the same time it is realised that the outsourced supplier has other customer enterprises to serve, so that there is a limit to what can be achieved, particularly when something goes wrong in the supply flow, into or out of the supplier. Lowest price alone cannot be the negotiating gambit with the supplier to retain services but a price based on an acceptable level of cooperation to reduce risk in the supply flow. Such cooperative arrangements should have heavy penalties for any defection from an agreed strategy.

Demand swings are another problem, and one which is highly probable in a fluid market place. Enterprises must make investment decisions at the right time to ensure new capacity is available on a demand upswing. Extra outsourced capacity may be difficult to come by when the economic cycle changes and this leads to longer order lead-times. Conversely if extra capacity is secured, through greenfield investments for instance, and demand shows no sign of increasing, this extra cost is an economic burden to an enterprise. Enterprise alliances are becoming more common to offset this risk. 
Inside the core enterprise, management of the supply chain has gained increased importance, elevating the logistics manager to director levels in some organisations. No plan can be accurate because it is about anticipating the future in a highly dynamic environment. However, customer delivery date promises, and logistic supply plans should reflect in a much better way, than most current systems provide, the detail of the information available, and can provide good control possibilities. Such controls need to have intelligent decision-making as the basis and take into account the influence on flow through the supply network. Local autonomies, such as manufacturing shop floors and factories, warehouses, and transport providers, will have to be constrained to work within specific guidelines to ensure co-ordinated actions throughout the supply network. A decisionmaking process may be automatic in certain instances, in others a rich choice of information and decision possibilities should be presented interactively to the assigned decision maker(s), with an ability to check consequential effects before any real decision is made, and in other instances an early warning may be sent upstream through the supply network to initiate possible control adjustments which may need prior negotiation. The way the decision-making processes are formulated and organised for control actions is one of the challenges to improved system design.

The trends are clear. Industrial enterprises have to change in both their internal and external perceptions in order to secure a confident future and competitive edge, but there is no easy solution to supply chain control, so trade-offs between conflicting requirements are very necessary. The way these tradeoffs are quantified will depend upon each enterprise involved and may be characterised by the industry to which it belongs.

\section{Trade-offs}

The changes described have had profound effects on the way manufacturing is planned, particularly along a supply chain. Three major opposing forces drive the planning process:

Variety: demanded by the customer may be achieved by flexible production techniques or high stockholding. Late customisation is another technique to achieve this aim with minimal compromise to lead times and inventories.

Short Lead Times: may be achieved by mass production techniques (at the expense of flexibility) or holding large stocks of finished or semifinished products through the supply network.

Low Inventories: allow responsiveness to changing market forces and improve a company's cash flow.

This triumvirate of forces is the basis of the most fundamental trade-off in tactical planning: working capital, in the form of inventory, vs. customer service (Fig. 1).

Holding stocks and inventories at advanced positions along the supply chain will, with diminishing returns, improve customer service but have negative financial effects by increasing working capital requirements, which consists of inventory costs, 
debtors and creditors. This is represented by the solid line in Fig. 1. Its shape, which is characteristic for a particular enterprise, will depend on forecast accuracy, lateness of customisation and how costs build up along the supply chain. The plan accuracy affects the curve too, since planners operating in uncertain environments will tend to build a lot of slack into the plan, translating to an increase in working capital need, whereas an unachievable plan will result in a loss of customer service. Ways of achieving a better plan along the supply chain are discussed in Section 5.

Planners tend to operate in a window (w) giving them acceptable levels of customer service and working capital. The trade-off curve may be improved in the direction of the dotted line by, for instance, improving forecasting, better use of capability or developing late customisation techniques. Such improvements will allow planners to decrease working capital (x), improve customer service (y), or both (z). Lot size has an effect on the working capital too, since large lots of one product represent a large investment and will tie up the capacity, but on the other hand may result in a smaller unit cost and a higher throughput by savings on set-ups. Attempts to improve customer service by expediting delinquent jobs must be traded off against the effect such expediting will have on other jobs. Such dynamic coupling is often not well understood.

To achieve lower customer order lead times some enterprises need to build or partbuild to forecast. Building to forecast is inherently risky; however, the risks may be attenuated by close co-operation with customers. Such co-operation must be traded off against the need to penetrate new markets and diversify the customer base. Particularly in high-tech industries, diversification can mean the allocation of substantial amounts of productive capacity to engineering, and the right balance between manufacturing and engineering must be assured.

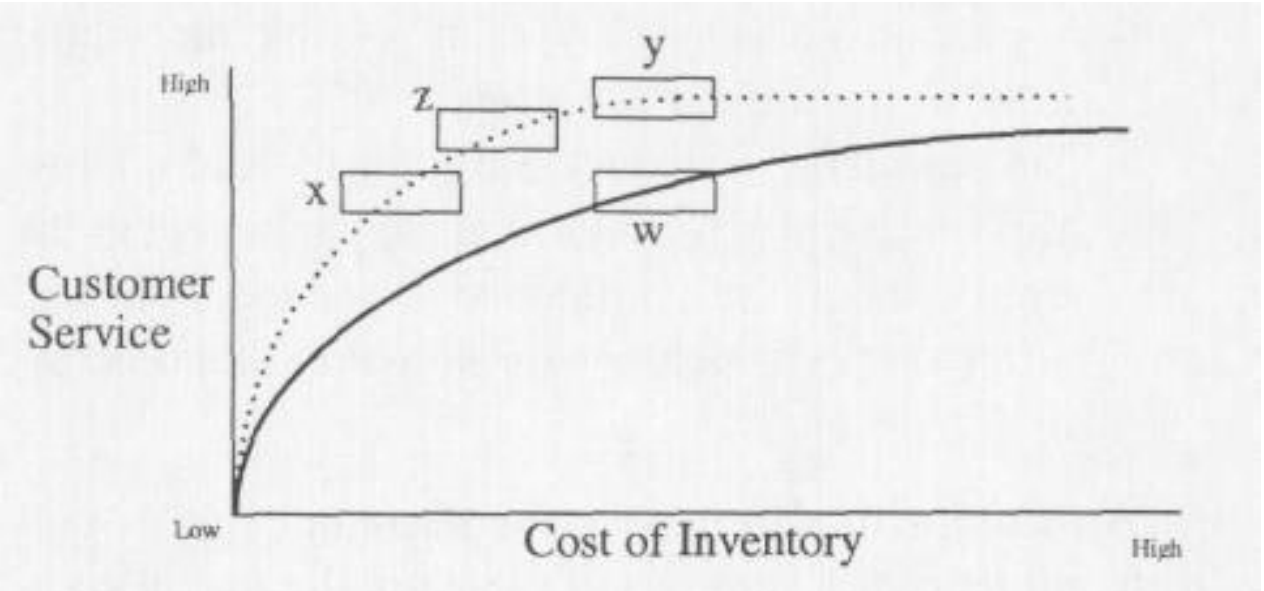

Fig. 1. Improving the service/inventory trade-off.

Fig. 1.

At the strategic level there is the 'make or buy' trade-off. A company can perform a particular part of manufacture by investment in fixed assets (machines or companies) or use working capital to pay somebody else to do it. A supply chain can consist of units owned by the core enterprise, units in a close 'partnership' with the enterprise 
and units and sites completely external to the enterprise. Long-term partnerships with suppliers may be beneficial to both parties, but may become onerous if the environment changes. For a company to choose between making in or outsourcing requires consideration of preservation of proprietary knowledge as well as economic factors.

Trade-offs are stated in very simple terms. However, in a real industrial situation, a lack of complete and concise information means that planners are often making decisions based on experience and 'gut feel'. This is one area where decision support systems must assist planners by providing accurate and timely responses to queries, allowing plans to make these trade-offs in a more informed way. The enabling process depends largely upon the degree of cooperation prevailing and it is here that we must turn to the virtual enterprise.

\section{The virtual enterprise}

A customer deals with one enterprise to secure an order and its delivery. In turn the vendor enterprise turns to other enterprises to assist in the order supply. The enterprises it directly deals with are under its primary sphere of influence as it acts as the core controlling enterprise. Many core enterprises today are trying to reduce the number of enterprises they have to deal with, from many hundreds, to levels by which better co-operative agreements may be negotiated. Each of these enterprises in turn may have their own supply sphere of influence, but this is secondary to the core enterprise vendor. It is the primary sphere of influence which is its main concern.

The primary sphere of influence may be termed a virtual enterprise providing that the degree of cooperation is acceptable, such that the core enterprise may exert some controlling influence. As mentioned previously there are three types of unit within the virtual enterprise. These are the wholly owned elements, which may be manufacturing process, tooling supply, transport, etc.; material, tooling or equipment suppliers; and service providers. Outsourced service suppliers can deal with manufacturing processing, warehouse storage and logistic transport. In many cases these may be liberally distributed throughout the whole, and often globally distributed, manufacturing supply network of the virtual enterprise. It is the effective use of capacity, a highly dynamic quantity (dependent upon many parameters, including product mix, capabilities and the uncertainties prevailing) including that of service providers, that causes the most concern for core central planning and control of the virtual enterprise. Control here means all of its aspects, from policies, power of directing activity and the action to bring into line with planned targets.

A key problem is how this manufacturing network of the virtual enterprise may be effectively tuned to make better use of its capabilities, negotiated or otherwise, to improve both customer service and core enterprise performance, through better management of the supply chain and planning and control actions.

\section{Proactive planning and reactive control}

Two current weaknesses in planning are: 
1. Planning is usually done using very rough models of capacity, and often based on the capabilities of one unit only, other units having to adapt to the plan.

2. Deviations from plan in one unit or site are communicated late or not at all to other units who may be affected by them.

These general problems call for two solutions viz.:

- proactive planning,

- reactive control.

An analogy for the problem of planning the supply chain can be seen in Fig. 2. The capacity of a unit (or the capacity reserved for a particular supply chain) will depend on the product mix, and this will affect the networked units in different ways. Thus, units may be illustrated as different shaped 'holes' with the area of each hole equal to the capacity of a unit. The problem of planning can be seen as deciding an amount (size) and mix (shape) of products to 'pass through' each unit (hole). It is common to choose a product mix to suit the capabilities of one unit, e.g., mix 1. Though this product mix gives maximum throughput at site 1, much less can go through sites 2, 3 and 4 in a given time period and yet much of their capacity will be unused. So products will be delayed despite the plan being apparently within capacity (i.e., the areas of the holes are large enough) for all sites. The trick is to find a product mix such as mix 2, which gives optimal production at all sites, whilst remaining within their actual capacity, so preserving lead times.

The ability to produce such a plan assumes a good understanding of the relationship between product mix and capacity for all units in the supply chain. Good capacity models of the stages in a supply chain, expressing the relationships between product mix, loading and lead times, are required.

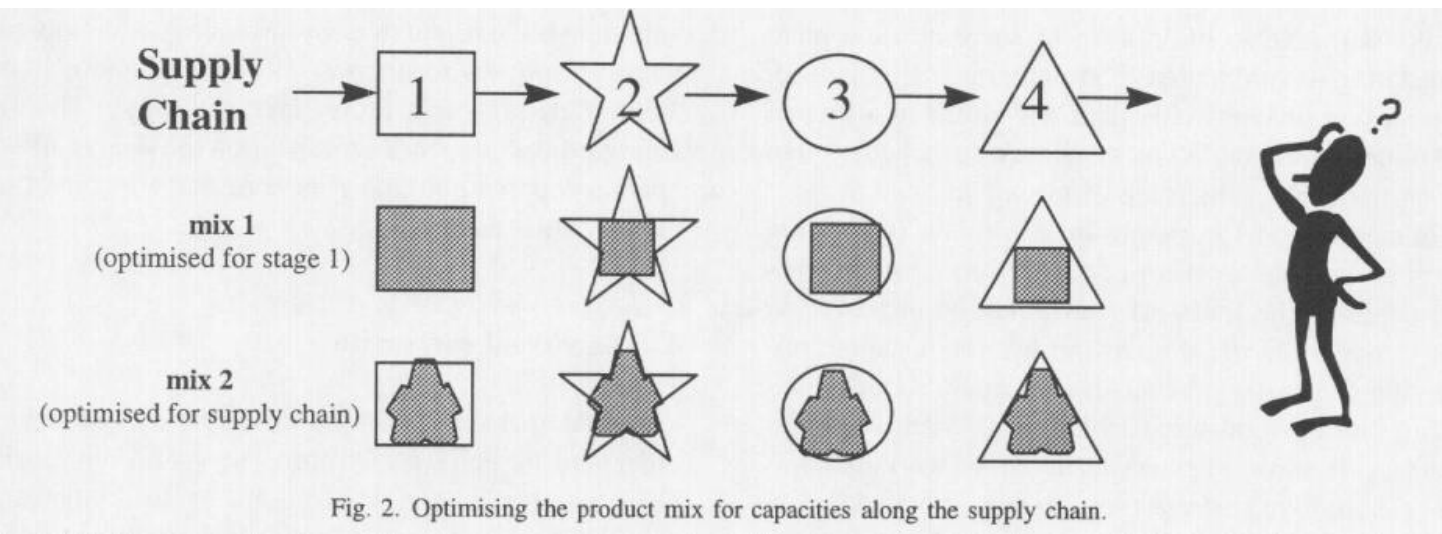

Fig. 2.

Once a plan, even a feasible plan as generated above, has been made and communicated to the virtual enterprise there is one and only one certainty about it: it will be wrong once initiated. The reason for this is that the assumptions made at the time of plan formulation are very likely to have changed. Such assumptions may include lack of consideration of transient resource availability, yields fluctuations, 
customers changing their orders, and so on. Timely reaction to such events will allow agreed customer due dates to be met by making minimal alterations to the plan along the supply chain, for instance:

- giving downstream sites good notice of altered schedules to allow them to change their reserved capacity;

- changing dates within the supply chain to still meet new customer requirements.

- Furthermore, in the case of an uncontrolled event resulting in not meeting of a customer order delivery date-time, the enterprise must be able to give the customer good notice of a new and realistic delivery expectation.

Reactive control will basically be required at three levels:

- Unit/Site level: a unit should be able to react to minor disturbances at an operational level so that interunit due dates are not jeopardised.

- Inter-unit/site: where control is not possible reaction at a tactical level between units should be facilitated to allow the supply chain to meet agreed deliveries.

- Core enterprise: in cases such as a customer cancelling, increasing or changing the due date of his order, a central facility should update all unit/sites in the supply chain.

A means and protocol for timely communication between the units is required for reactive control, as well as methodology for the meaningful use of this information in the context of the individual supply chain.

\section{Current IT solutions}

Problems are encountered in realising global goals due to large gaps that exist between higher level planning systems and local execution of tasks. There are no commercially available systems or tools that completely address the needs of the complex planning and control processes that virtual enterprises are faced with.

The lack of commercial multi-site-planning solutions has spawned many bespoke solutions, some for semiconductor virtual enterprises. Leachman et al. [2] describe the IMPReSS system at Harris Semiconductors. The master production schedule, MPS, is generated by a series of linear programming models which take into account the choices in the manufacturing network. The capacity model uses a resource profile method [3] for 'validating' an MPS, using a single bottleneck resource and re-entrant flow. Duenyas et al. [4] report on, inter alia, a planning implementation at Toshiba's semiconductor plant using mean value analysis of queuing networks, MVAQ [5]. This system was implemented across the virtual enterprise by installing it at all sites, even those not owned by Toshiba. The weakness of this system is that it is unable to predict the behaviour of individual lots so a second system based on discrete event simulation was developed to check whether important lots were likely to meet due dates and adjust lot priorities accordingly. 
Commercial solutions are based on the concepts of MRP-II. Such solutions are known as Enterprise Resource Planning (ERP). Such planning systems for globally distributed manufacturing enterprises are foremost large database systems that are built around order processing. An Master Production Schedule (MPS) is generated without any capacity considerations, based only on demand and forecasts. Start dates for the various unit/sites in a virtual enterprise manufacturing network, are estimated from customer order required dates by offsetting unit-unit lead time standards, at the same time taking into account any uncommitted inventory availability. Rough cut capacity planning is in some cases used to 'validate' an MPS. Additionally, heuristic guides or spreadsheet models are sometimes used to try to ensure feasibility of the MPS. This may be for example allowing a sufficient product mix-dependent slack time. Finally, the large amount of data involved renders the production of an MPS a very tedious process, performed at infrequent time intervals.

A survey of Aggregate Production Planning methods from 170 journal articles and 13 books is found in [6]. Mennekens et al. [7] give a detailed exposition of the calculation of Master Production Schedules across the functions of an enterprise. This system was developed under the Esprit project E6588. The resulting system deals mainly with the concurrent enterprise planning by generating an enterprise-wide master production schedule. There are also interfaces to existing material requirements planning and resource capacity planning systems. However, although a higher level of integration has been achieved with this system, it still remains a bespoke solution.

Another problem is that shop floor release regulators and schedulers as well as manufacturing execution systems, have been developed separately. There are, however, a number of solutions, many objectoriented, some of which are commercially available, but are not integrated with the higher planning systems and consequently do not work together in a consistent and coherent manner. Integration is a challenge which the semiconductor industry organisation SEMATECH are currently seeking to establish and promote through a computer-integrated manufacturing framework standard dealing with heterogeneous legacy systems and different application software packages.

\section{A case study}

Semiconductor manufacturing involves the transformation of raw silicon wafers into fully functional and packaged integrated circuits. Processes involve hundreds of steps taking many days of process time. At the front end of processing, called wafer fabrication silicon die, of the size characteristic to the product, are batch processed through many stages involving photoprinting, thermal diffusion, ion implantation, and layer depositions, including the metal interconnect patterns. Individual dies are then tested, to sort out good dies from bad as integrated circuit production has yield as one of its main variables. Finally, the good die are separated into chips and assembled in special packaging associated with the specific product design or customer preference, before finally rigorously testing each packaged product, taking into account customer needs, prior to customer shipment. 
The main difference of this type of industry is that it is characterised by processing silicon wafers in different ways to produce a wide range of products. A large number of different technologies are involved for an enterprise product portfolio. Many different product routes are possible involving a number of different shop floors and processing activities. Manufacturing enterprises have a number of different facilities for wafer fabrication, assembly and final testing. Such enterprises are often multinational and are closely coupled in partnerships with suppliers, subcontractors and customers and in this industry, there are many examples of enterprises which have grown by acquisition resulting in cultural and system differences which have yet to be resolved. Semiconductor enterprises may also be part of a larger company, such as a large electronics corporation which may impose its financial control.

A distinctive characteristic of this type of industry is a very high requirement for capital investment, which is continuous and ever more demanding with regular introduction of more advanced technologies to satisfy product ambitions and opportunities. Inevitably shared investments and facilities of two or more competitive enterprises are now common place to offset commercial risk. It is also very common to employ suppliers of services. Such outsourcing may involve any of the stages for integrated circuit manufacture, including design, wafer fabrication, assembly, final test, sales and distribution and so on.

Clearly, semiconductor virtual enterprises comprise a global manufacturing network hinging on alliances, service suppliers and distributed wholly owned facilities. The different routing options within the network are product- and capability-dependent. A customer order may consist of a number of product line items to be delivered either in a set, a so-called kit-of-parts, or assembled within the same package, termed multichip-module (MCM). The order components are invariably supplied from different product routes, including different stocking localities and regional sales areas. It is a substantial job for any planning and control system to secure whole customer orders delivered on time, with an acceptable order lead-time and a controlled use of working capital. 


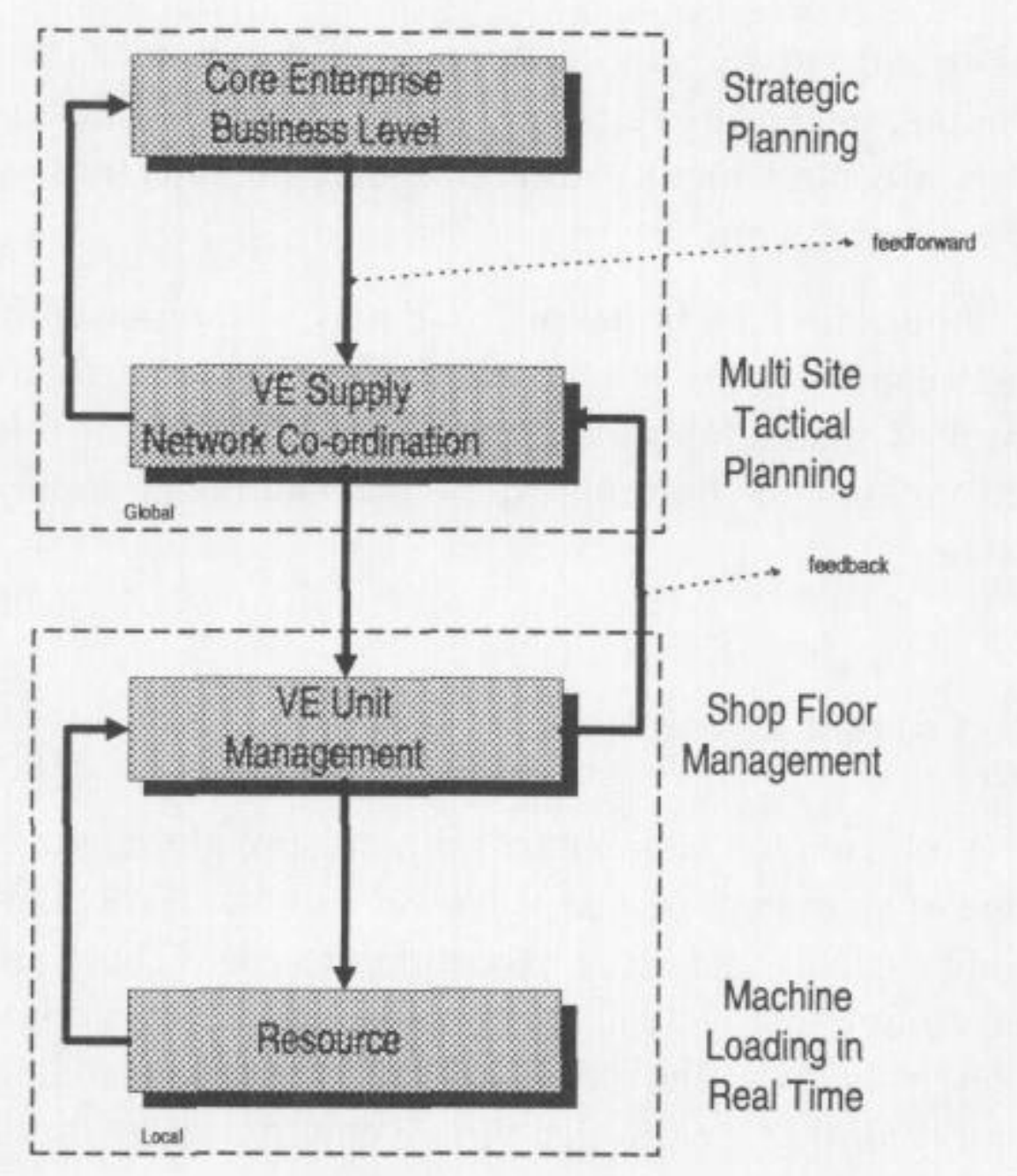

Fig. 3. Planning hierarchy.

Fig. 3.

Currently, order entry is one of the processes which can be performed in an uncoordinated fashion. Sales departments may try to satisfy a customer as much as they can and therefore prefer to take customer request dates as the date they want the order to be delivered without taking into account the ability to deliver such promises, i.e., taking into account the network capacities, inventory status and any other known constraints. Improved planning processes need to promise customers realistic delivery dates which can be adhered to in order to establish the necessary confidence and continuing customer loyalty.

To improve customer service, many core enterprises aim to reduce their order lead times by keeping strategic partially processed products in inventory. These products are either determined by forecast demand or possibly sometimes by business agreements with strategic customers, which may take place before confirmation of orders. Die yield variations can also supplement intermediate stock holdings. These practices, although allowing shorter lead times, are subject to many uncertainties, leading to increased risks of high inventory and working capital requirements. 
The Esprit Project 20544, entitled X-CITTIC, aims to address existing gaps in planning and control for a virtual enterprise by provision of a highly flexible and adaptable toolset which can be integrated with existing systems [8]. X-CITTIC will eventually provide solutions to improve manufacturing performance, by integrating the heterogeneous manufacturing systems and by bridging the gap between the higher business planning levels and the lower local and autonomous shop floor control level.

Figure 3 shows the proposed planning and control hierarchy for a virtual enterprise. This diagram shows an adopted version of the hierarchical control model presented in [9], to suit the needs of the Virtual Enterprise. At the core enterprise business level, customer order entry and top level planning, including business and budget planning takes place. Subordinate to that level is the virtual enterprise supply network coordination level. This is the global planning component of X-CITIC. Both the corporate and the enterprise network levels are global systems and hence they both have visibility across the virtual enterprise.

Moving vertically through the hierarchy, two more levels can be identified, the Virtual Enterprise unit management level and the resource level. At the Virtual Enterprise unit management level the local XCITTIC component resides together with the local, manufacturing execution system, MES. At this level, scheduling and order tracking in real time take place for the particular Virtual Enterprise unit in question. This suggests that the X-CITrIC components that relate to a Virtual Enterprise unit are integrated together and co-ordinated by the global level, and also that they are elements of the distributed X-CITTIC toolset. Finally, at the lowest level, machine loading in real time takes place. Both the Virtual Enterprise supply network coordination and the Virtual Enterprise unit management levels involve tactical planning. At these two levels the X-CIT[IC global and local components reside and they serve the purposes of bridging the gap between global level planning, and local execution of tasks. Horizontally, the virtual enterprise can be modelled as a network consisting of processing stages, stores and logistic transport stages, integrated together by the X-CITTIC system. 


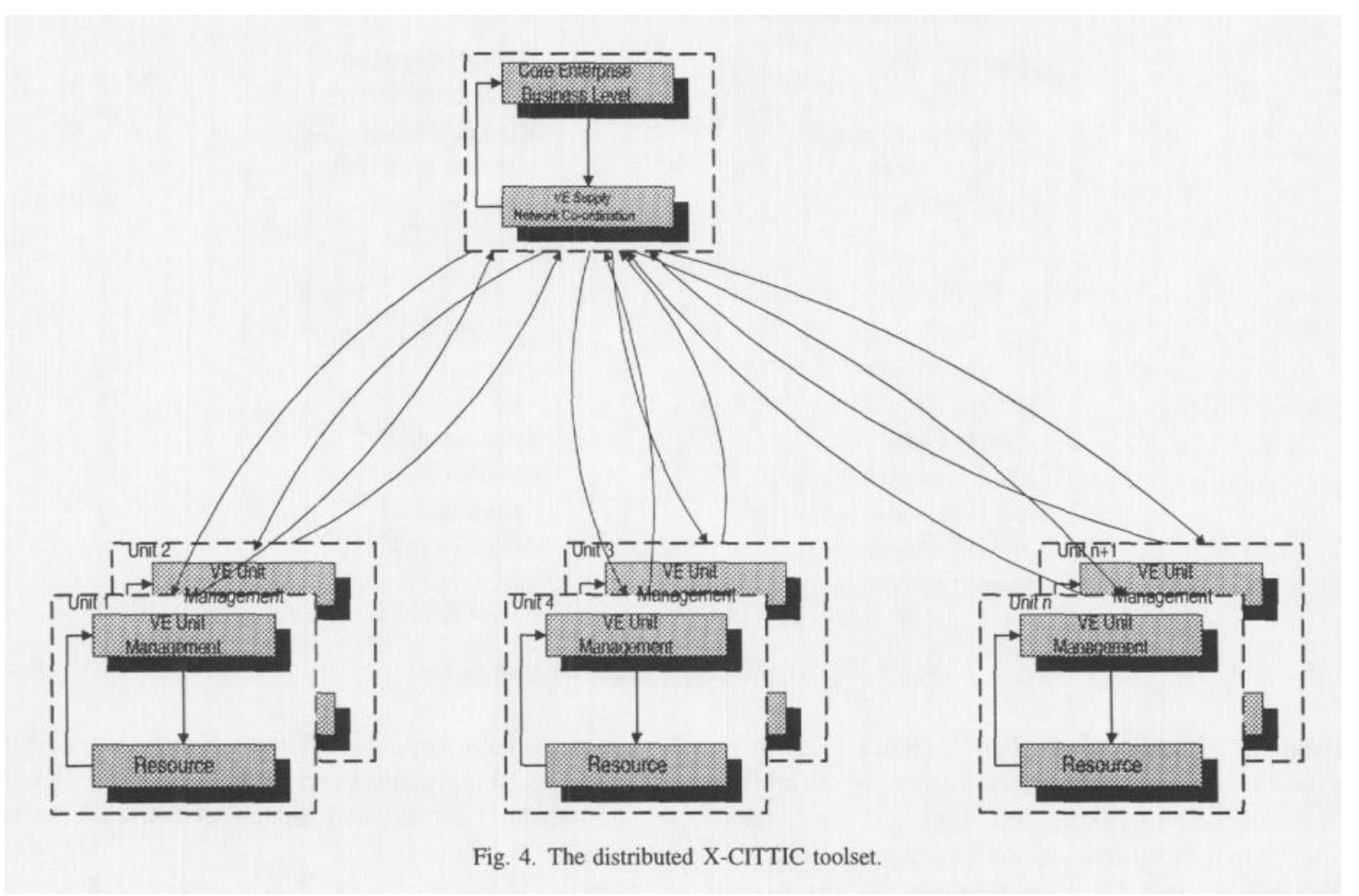

Fig. 4.

The X-CITTIC system is shown in Fig. 4. At the enterprise network level, the global component of XCITRIC resides. This system component is responsible for generating a schedule for the Virtual Enterprise supply network. Such a schedule takes into account manufacturing units as well as transportation and logistics. Suitable production targets for each unit in the network are then based on state, capability and capacity constraints. Inventory levels in the network are optimised at the same time in terms of minimising both the risk of inventory shortages and inventory holding. Timely, accurate and relevant information is fed back to the corporate level for customer delivery agreements. Additionally, where a choice of subcontractors or alternative processing units exist internal to the core enterprise, the best routing is determined in the Virtual Enterprise schedule generation phase.

When the production requirements for each unit have been determined each unit then becomes fully responsible to meet the production requirements assigned to it. But semiconductor manufacturing is highly dynamic and the occurrence of unplanned events are quite frequent. So, reactive response to unplanned events must be in good time to limit any deviations from the plan. The local X-CITTIC component is thus responsible for monitoring progress of the work and in case of deviations to the original plan to provide reactive plan repair. Reactive plan repair will take place by means of horizontal negotiation between the Virtual Enterprise units in question to resolve any conflicts and repair the current plan in response to unplanned events. This component will provide processes for both automated decision-making and valuable assistance to the planning and logistics personnel of the core enterprise. 
Dealing with the vast amount of information residing in the virtual enterprise demands a fluid approach to content retrieval. X-CITIC utilises for enterprise order management an approach which is both responsive and directed involving intelligent processing through full object orientation and agent-based architecture. Besides these agents the architecture for X-CITTIC contains a variety of components which serve connection to legacy systems, special functional software, knowledge-based problem solving and interactive decision support software. Functional user interfaces will allow informed decision-making to manage customer service and aspects of financial performance.

\section{Conclusions}

A hundred years ago we had the business entrepreneur, a central intelligence who planned and coordinated a number of independent and autonomous enterprises to produce products for sale. Improvements to manufacturing methods came early this century in the form of early mass production. With 'Fordism' came vertical integration, economies of scale and control by attempting to own all stages of supply. Eventually, diseconomies of scale and inefficiencies within the enterprise caused by a complete lack of competitive pressures caused a turnaround with enterprises divesting everything except core competencies with the held belief that aggressive competitive supply pressures would bring about improvements. Such visions were short-lived, and customer supplier relationships had to be improved for mutual benefit in terms of quality of service and supply. As we approach the new millennium we see a necessary return to former systems to control the supply chain. That is, a central intelligence planning and co-ordinating independent autonomous companies to realise the benefit to them and to the core enterprise customer (Fig. 5). The process of this change will begin at the co-operative virtual enterprise we have discussed here.

The system proposed brings with it the benefit of integrating with current solutions to secure enhanced planning performance and control precision. Such improvements will bring benefit to the customer in improved service and confidence to reduce inward stocks. It will also bring benefit to the core enterprise in utilisation of working capital and capacities available to improve its competitivity and profitability. 
Entrepreneur

Co-ordinate, allowing everyone a portion of the final profit margin

Supply Chain

Protect and grow our margins in a cooperative way as a

virtual enterprise
Vertical Integration

Buy up as many stages of production as possible to get the full margin

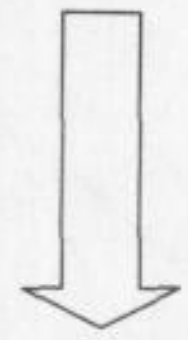

Fragmentation

Divest to core competencies, maximising profit margin at the expense of all others

Fig. 5. Manufacturing paradigms of the past century.

Fig. 5. 


\section{References}

[1] A.D. Chandler, Jr. and D. Alfred, Scale and Scope: The Dynamics of Industrial Capitalism, First Harvard University Press, 1990.

[2] R.C. Leachman, R.F Benson, C. Liu and D.J. Raar, IMPReSS: an automated production planning and delivery quotation system at Harris Corporationsemiconductor sector, Interfaces 26 (Jan./Feb. 1996).

[3] J.C. Wortman, M.J. Euwe, M. Taal and VC.S. Weiss, A review of capacity planning techniques within standard software packages, Production Planning and Control 7(2) (1996).

[4] I. Duenyas, J.W. Fowler and L.W. Schruben, Planning and scheduling in Japanese semiconductor manufacturers, Journal of Manufacturing Systems 13(5) (1994).

[5] R. Suri and R.R. Hildebrant, Modelling of FMSs using Mean-Value Analysis, Journal of Manufacturing Systems 3(2) (1984).

[6] S.-J. Nam and R. Logendran, Aggregate production planning A survey of models and methodologies, European Journal of Operational Research 61 (1992).

[7] E. Mennekens, E. Nollet and M. Hudd, Integrated enterprise planning and logistics management, Alcatel Bell Central Planning Department, 1994.

[8] C. Makatsoris, N.P. Leach, H.D. Richards, C.B. Besant and M. Ristic, Addressing the planning and control gaps in semiconductor virtual enterprises, in: Esprit Integration in Manufacturing Conference, Galway, Ireland, 2-4 October 1996.

[9] C. Makatsoris, Planning, Scheduling and Control for Distributed Manufacturing Systems, PhD Thesis, University of London, 1996. 